\title{
Sequential treatment with celecoxib and bortezomib enhances the ER stress-mediated autophagy-associated cell death of colon cancer cells
}

\author{
GA-BIN PARK $^{1 *}$, DONG-HOON JIN ${ }^{2,3 *}$ and DAEJIN KIM ${ }^{4}$ \\ ${ }^{1}$ Department of Biochemistry, Kosin University College of Medicine, Busan 49267; \\ Departments of ${ }^{2}$ Convergence and ${ }^{3}$ Oncology, University of Ulsan College of Medicine, Asan Medical Center, \\ Seoul 05505; ${ }^{4}$ Department of Anatomy, Inje University College of Medicine, Busan 47392, Republic of Korea
}

Received April 10, 2017; Accepted July 21, 2017

DOI: $10.3892 /$ ol.2018.9233

\begin{abstract}
Treatment with celecoxib and bortezomib as single chemotherapeutic agents reduces the viability and proliferation of colorectal cancer cells. The use of these agents in combination with other chemotherapeutic agents is usually associated with adverse effects. In the present study, a combination of celecoxib and bortezomib was investigated for potential synergistic effects in colon cancer cells. The sequential exposure to celecoxib with bortezomib synergistically induced apoptotic death in human colon cancer cells compared with groups treated with a single drug or other drug combinations. c-Jun N-terminal kinase/p38-mitogen-activated protein kinase-induced endoplasmic reticulum (ER) stress through serial exposure to celecoxib and bortezomib may have induced the intracellular $\mathrm{Ca}^{2+}$ release, leading to the generation of autophagosomes in p53-expressing HCT-116 cells. Targeted inhibition of p53 activity or ER stress or treatment with the $\mathrm{Ca}^{2+}$-chelating agent BAPTA-AM suppressed the ER stress-mediated $\mathrm{Ca}^{2+}$ release and apoptosis. Although $\mathrm{p} 53^{-1-}$ HCT-116 cells were less sensitive to sequential treatment with celecoxib and bortezomib, co-localization of autophagosomes was detected in the absence of CCAAT-enhancer-binding protein homologous protein expression. Treatment of $\mathrm{p}^{-1-}$ HCT-116 cells with BAPTA-AM did not inhibit apoptosis following serial treatment with celecoxib and bortezomib. These results suggest that the order of drug administration is important in treating cancer and that the sequential treatment with celecoxib and bortezomib enhances the ER stress-mediated
\end{abstract}

Correspondence to: Dr Daejin Kim, Department of Anatomy, Inje University College of Medicine, 75 Bokji Street, Busanjin, Busan 47392, Republic of Korea

E-mail: kimdj@inje.ac.kr

*Contributed equally

Key words: celecoxib, bortezomib, endoplasmic reticulum stress, autophagy, colon cancer, p53 autophagy-associated cell death of colon cancer cells, regardless of p53 expression.

\section{Introduction}

Celecoxib, a cyclooxygenase-2 (COX-2)-specific inhibitor, reduces the risk of colorectal cancer, exhibiting anti-proliferative and chemoprophylactic effects on this cancer $(1,2)$. Treatment with celecoxib induces the upregulation of endoplasmic reticulum (ER) chaperones, and promotes tumor cell death in vitro and in vivo through the ER stress response $(3,4)$. This ER stress induces the nuclear phosphorylation and activation of p53, leading to ER stress-induced cell death in MCF-7 and HeLa cells (5). The co-treatment of p53-deficient colon cancer cells with zerumbone and celecoxib also induces ER stress and the transactivation of death receptor 5 (DR5) (6). The underlying molecular mechanisms by which celecoxib inhibits each cancer type have yet to be completely characterized. Therefore, it is necessary to investigate the downstream signaling pathways induced by treatment with celecoxib for clinical applications, and to examine whether it is more efficacious to treat cancer with a combination of drugs, rather than celecoxib alone.

The proteasome inhibitor bortezomib is a promising candidate for the treatment of hematological and solid cancer types (7). Bortezomib induces the unfolded protein response (UPR) to a limited extent, whereas the induction of binding immunoglobulin protein (BiP) and CCAAT/enhancer binding protein homologous protein (CHOP) by an ER stress-inducing agent is attenuated following exposure to this drug (8). Bortezomib activates downstream targets of $\mathrm{p} 53$, including p21, p53-upregulated modulator of apoptosis (PUMA) and Bcl-2-associated X (Bax); however, the induction of apoptosis by bortezomib is not affected by the deletion of p53 in colon cancer cells (9). Autophagy can protect cells from apoptotic stimuli, including growth factor deprivation and ER stress $(10,11)$. Autophagy may also induce cell death, as the components of the autophagic and apoptotic machinery are interconnected and shared (12). The inhibition of cisplatin-induced autophagy by bortezomib has been shown to enhance the chemotherapeutic efficacy of cisplatin in ovarian 
cancer (13). The autophagy inhibitor 3-methyladenine (3-MA) enhances celecoxib-induced apoptosis in human colon cancer cells (14). On the basis of these reports, the effect and underlying mechanism of bortezomib or celecoxib on the induction of p53- and ER-stress-associated apoptosis in cancer cells remain controversial. Furthermore, the role of autophagy in cancer cells is complex and highly cell-type-dependent.

Despite the established connections between bortezomib or celecoxib treatment with ER stress or autophagy, it has yet to be determined whether combination treatment with celecoxib and bortezomib can improve the efficacy of treatment in colon cancer treatment by further promoting ER stress/autophagy-associated cell death. The present study focused on the development of novel chemotherapy combinations containing celecoxib and bortezomib for the treatment of colon cancer; it investigated whether the order of administration was critical for the induction of ER stress or stimulation of autophagy-associated cell death in colon cancer cells. In addition, the present study attempted to identify the role of p53 in the ER stress-mediated autophagy signaling pathway following the combination of celecoxib with bortezomib in HCT-116 and p53 ${ }^{-/-}$HCT-116 cells.

\section{Materials and methods}

Cell lines and reagents. The HCT-116, HCT- 8 and HT-29 human colorectal cancer cell lines were purchased from the American Type Culture Collection (Manassas, VA, USA). p53 ${ }^{-/}$HCT-116 cells were kindly provided by Professor Bert Vogelstein (Johns Hopkins University, Baltimore, MD, USA). All cells were maintained in RPMI-1640 medium (Corning Incorporated, Corning, NY, USA) supplemented with 10\% FBS (HyClone; GE Healthcare, Chicago, IL, USA), streptomycin and glutamine at $37^{\circ} \mathrm{C}$ in $5 \% \mathrm{CO}_{2}$. Bortezomib was purchased from LC Laboratories (Woburn, MA, USA). Celecoxib was obtained from Selleck Chemicals (Houston, TX, USA). SP600125, a c-Jun N-terminal kinase (JNK) inhibitor, SB203580, a p38-mitogen-activated protein kinase (MAPK) inhibitor and salubrinal, an ER stress inhibiter, were purchased from Calbiochem (Merck KGaA, Darmstadt, Germany). BAPTA-AM and 3-MA were obtained from Sigma-Aldrich (Merck KGaA). Pifithrin (PFT)- $\alpha$ was purchased from Santa Cruz Biotechnology, Inc. (Dallas, TX, USA). To inhibit the activation of JNK or p38-mitogen-activated protein kinase, cells were pre-treated with SP600125 $(20 \mu \mathrm{M})$ or SB203580 $(10 \mu \mathrm{M})$ for $2 \mathrm{~h}$ at $37^{\circ} \mathrm{C}$. To block endoplasmic reticulum stress, cells were pre-incubated with salubrinal $(2 \mu \mathrm{M})$ for $1 \mathrm{~h}$ at $37^{\circ} \mathrm{C}$. To inhibit the autophagic signal, cells were pre-treated with 3-MA $(10 \mathrm{mM})$ for $2 \mathrm{~h}$ at $37^{\circ} \mathrm{C}$. To block the expression of p53, cells were pre-exposed to PTF- $\alpha(50 \mu \mathrm{M})$ for $1 \mathrm{~h}$ at $37^{\circ} \mathrm{C}$. To inhibit the effect of $\mathrm{Ca}^{2+}$, cells were pre-treated with BAPTA-AM $(2 \mu \mathrm{M})$ for $30 \mathrm{~min}$ at $37^{\circ} \mathrm{C}$.

Cell viability assay with AlamarBlue and Cell Counting kit- 8 (CCK-8). HCT-116, HCT-8 or HT-29 cells ( $2 \times 10^{4}$ cells/well) were seeded in RPMI-1640 containing 10\% FBS in 96-well plates. Cells were pre-treated with bortezomib $(20 \mathrm{nM})$ for $6 \mathrm{~h}$ and then treated with celecoxib $(20 \mu \mathrm{M})$ for an additional $18 \mathrm{~h}$. For comparison, cells were treated either with bortezomib $(100 \mathrm{nM})$ or celecoxib $(80 \mu \mathrm{M})$ alone or co-treated
(20 nM bortezomib $+20 \mu \mathrm{M}$ celecoxib) for $24 \mathrm{~h}$. Finally, cells pre-exposed to celecoxib $(20 \mu \mathrm{M})$ for $6 \mathrm{~h}$ were then treated with bortezomib $(20 \mathrm{nM})$ for $18 \mathrm{~h}$.

Cell viability was measured using an AlamarBlue assay (Serotec; Bio-Rad Laboratories, Inc., Hercules, CA, USA). AlamarBlue was added ( $10 \%$ by volume) to each well, and the relative fluorescence unit (RFU) values were determined $7 \mathrm{~h}$ later using a SpectraMax M2e Multi-Detection Microplate Reader (excitation, $530 \mathrm{~nm}$; emission, $590 \mathrm{~nm}$; Molecular Devices, LLC, Sunnyvale, CA, USA). Experiments were performed in triplicate, and RFU values were expressed as the mean \pm standard deviation (SD) of three replicates.

Cell viability was also measured using a CCK- 8 assay (Sigma-Aldrich; Merck KGaA) according to the manufacturer's protocol. Briefly, HCT-116, HCT-8 or HT-29 cells $\left(2 \times 10^{4}\right.$ cells/well) in 96 -well plates were pre-treated with celecoxib $(20 \mu \mathrm{M})$ for $6 \mathrm{~h}$ and then with bortezomib $(20 \mathrm{nM})$ for an additional $18 \mathrm{~h}$. For comparison, cells were treated with celecoxib $(80 \mu \mathrm{M})$. At $24 \mathrm{~h}$, the cells were stained with $10 \mu \mathrm{l}$ CCK- 8 dye in $90 \mu \mathrm{l}$ of culture medium for $2 \mathrm{~h}$ at $37^{\circ} \mathrm{C}$. The absorbance was measured at $450 \mathrm{~nm}$.

Analysis of apoptosis by flow cytometry. HCT-116 and $\mathrm{p} 53^{-1-}$ HCT-116 cells $\left(1 \times 10^{5}\right.$ cells $\left./ \mathrm{ml}\right)$ were cultured in 6 -well plates and pre-treated with $20 \mathrm{nM}$ bortezomib for $6 \mathrm{~h}$ and then with $20 \mu \mathrm{M}$ celecoxib for an additional $18 \mathrm{~h}$. For comparison, cells were treated either with $100 \mathrm{nM}$ bortezomib or $80 \mu \mathrm{M}$ celecoxib alone or co-treated ( $20 \mathrm{nM}$ bortezomib $+20 \mu \mathrm{M}$ celecoxib) for $24 \mathrm{~h}$. Finally, cells were pre-exposed to $20 \mu \mathrm{M}$ celecoxib for $6 \mathrm{~h}$ and then treated with $20 \mathrm{nM}$ bortezomib for $18 \mathrm{~h}$.

The percentages of cells undergoing apoptosis were determined by flow cytometry using fluorescein isothiocyanate (FITC)-labeled annexin-V and 7-aminoactinomycin (7-AAD) (both BD Biosciences, San Diego, CA, USA). Cells were harvested, rinsed with $\mathrm{PBS}$, and resuspended in $100 \mu \mathrm{l}$ of $1 \mathrm{X}$ annexin-V binding buffer (BD Biosciences). A total of $3 \mu \mathrm{l}$ annexin-V-FITC and $3 \mu \mathrm{l}$ 7-AAD were added, and cells were incubated at room temperature for $15 \mathrm{~min}$ in the dark, with gentle vortexing. The stained cells were analyzed using a FACSCalibur flow cytometer equipped with CellQuestpro software version 5.1 (BD Biosciences). Dot plot graphs were produced to quantify the percentage of viable cells (annexin- $\mathrm{V}^{-} / 7-\mathrm{AAD}^{-}$), early-stage apoptotic cells (Annexin- $\mathrm{V}^{+} / 7-\mathrm{AAD}^{-}$), late-stage apoptotic cells $\left(\right.$ annexin- $\mathrm{V}^{+} / 7-\mathrm{AAD}^{+}$) and necrotic cells (Annexin-V/7-AAD ${ }^{+}$).

Quantification of cytosolic and mitochondrial $\mathrm{Ca}^{2+}$ levels. Cytosolic $\mathrm{Ca}^{2+}$ levels were determined using the fluorescent dye Fluo3-AM (5 $\mu \mathrm{M}$; log mode in FITC setting; Molecular Probes; Thermo Fisher Scientific, Inc.). Mitochondrial $\mathrm{Ca}^{2+}$ levels were determined using the fluorescent dye Rhod2-AM (1 $\mu \mathrm{M}$; Molecular Probes; Thermo Fisher Scientific, Inc.). Cells were incubated with the fluorescent dyes for $20 \mathrm{~min}$ at $37^{\circ} \mathrm{C}$, washed with calcium-free Dulbecco's PBS, and analyzed by flow cytometry. For certain experiments, cells were pretreated with BAPTA-AM $(2 \mu \mathrm{M})$ for $30 \mathrm{~min}$.

Western blotting. Cells were washed in PBS and lysed in NP-40 buffer (Elpis Biotech, Inc., Daejeon, Korea) supplemented with a protease inhibitor cocktail (Sigma-Aldrich; Merck KGaA). 
A
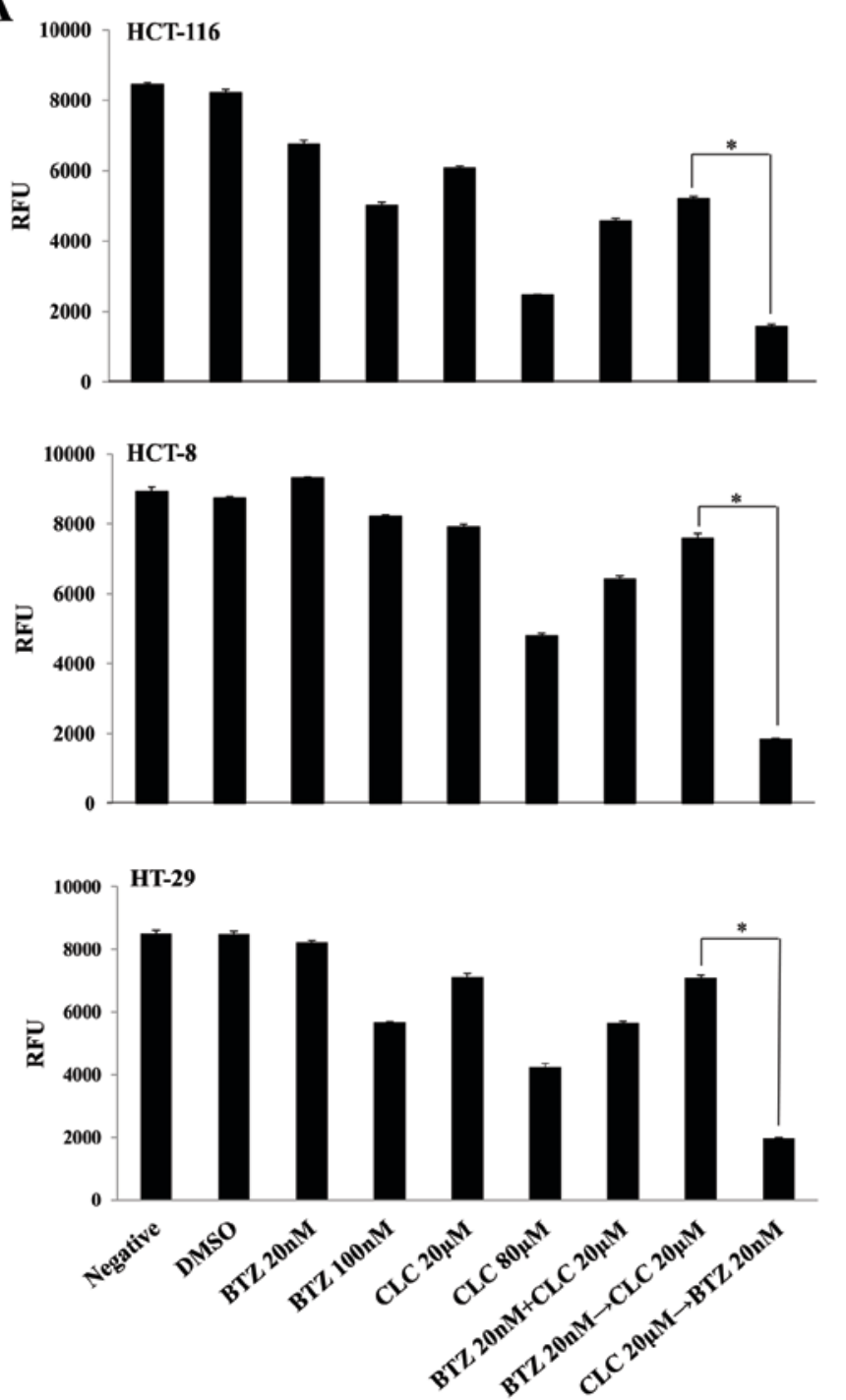

B
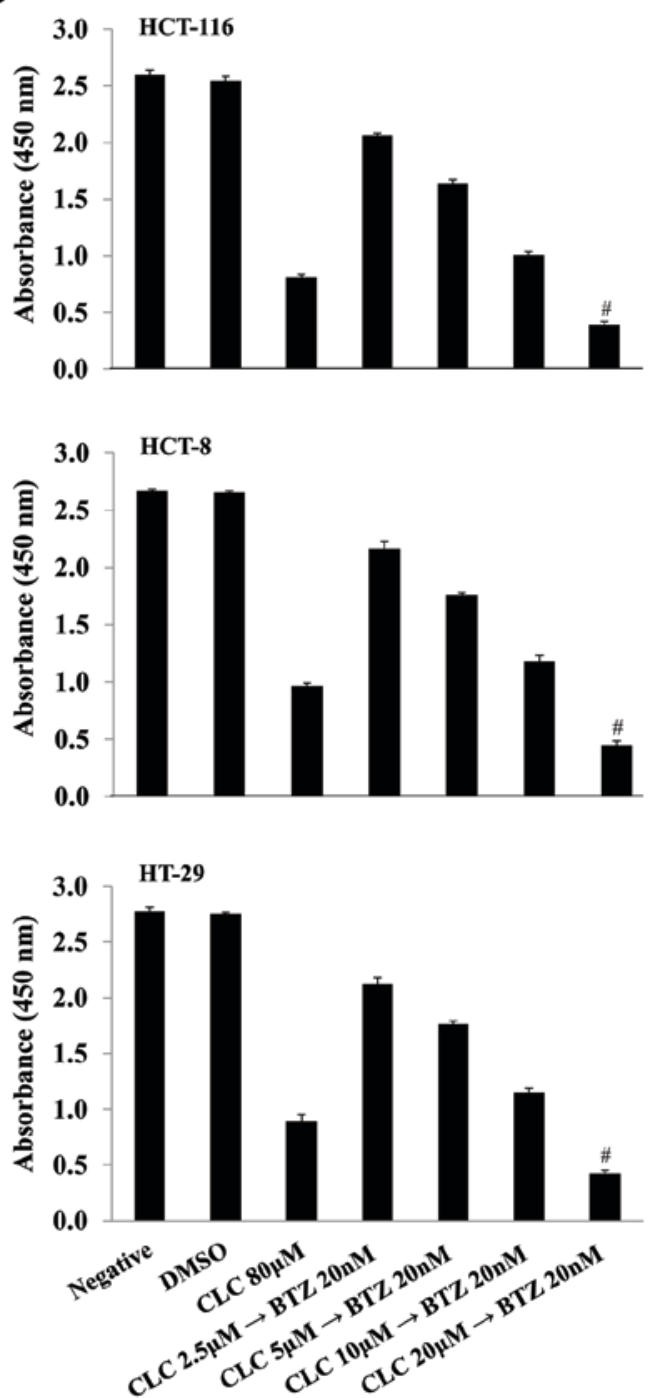

Figure 1. Effect of sequential treatment with CLC and BTZ on colorectal cancer cell survival. (A) Cells were treated with BTZ or CLC alone or in combination. Cell viability was measured using an AlamarBlue assay. The levels of fluorescence are presented. $n=3$. ${ }^{*} \mathrm{P}<0.01$. (B) Cells were sequentially treated with the indicated drug combinations for $24 \mathrm{~h}$. For comparison, cells were treated with $80 \mu \mathrm{M}$ CLC alone for $24 \mathrm{~h}$. Cell viability was also measured using a Cell Counting kit- 8 assay. The absorbance at $450 \mathrm{~nm}$ is presented. $\mathrm{n}=3 .{ }^{*} \mathrm{P}<0.01$ compared with CLC $2.5 \mu \mathrm{M}$ followed by BTZ $20 \mathrm{nM}$. CLC, celecoxib; BTZ, bortezomib; negative, non-treated cell; DMSO, dimethyl sulfoxide control; RFU, relative fluorescence unit.

Protein phosphorylation states were preserved through the addition of phosphatase inhibitors (Cocktail II; Sigma-Aldrich; Merck KGaA) to the NP-40 buffer. Protein concentrations were determined using a BCA assay kit (Pierce; Thermo Fisher Scientific, Inc., Waltham, MA, USA). Proteins (10 $\mu \mathrm{g} / \mathrm{lane}$ ) were resolved through SDS-PAGE (12\%) and transferred to a nitrocellulose membrane (EMD Millipore, Billerica, MA, USA). Membranes were blocked with $5 \%$ skimmed milk for $1 \mathrm{~h}$ at room temperature prior to western blot analysis. The following primary antibodies were used: Caspase-3 (cat. no. 9665; 1:1,000), caspase-9 (cat. no. 9502; 1:1,000), poly (ADP-ribose) polymerase (PARP; cat. no. 9542; 1:1,000), $\beta$-actin (cat. no. 4967; 1:1,000), Bcl-2 (cat. no. 2870; 1:1,000), Bax (cat. no. 2772; 1:1,000), Bcl-2 homologous antagonist/killer (Bak; cat. no. 6947; 1:1,000), Mcl-1 (cat. no. 4572; 1:1,000), Puma (cat. no. 4976; 1:1,000), survivin (cat. no. 2808; 1:1,000), p53 (cat. no. 2524; 1:1,000), phosphorylated (p)-extracellular-related kinase (ERK)1/2 (Thr ${ }^{202} / \mathrm{Tyr}^{204}$; cat. no. 9101; 1:1,000), ERK1/2 (Tyr ${ }^{925}$; cat. no. 9102; 1:1,000), p-p38-MAPK ( Thr $^{180} / \mathrm{Tyr}^{182}$; cat. no. 9211; 1:1,000), p38-MAPK (cat. no. 9212; 1:1,000), p-JNK (Thr ${ }^{183} /$ Tyr $^{185}$; cat. no. 4671; 1:1,000), JNK (cat. no. 9258; 1:1,000), Beclin-1 (cat. no. 3495; 1:1,000), microtubule-associated protein 1A/1B-light chain 3 (LC3)-I/II (cat. no. 4108; 1:1,000). These antibodies were purchased from Cell Signaling Technology (Beverly, MA, USA), and CHOP (Santa Cruz Biotechnology, Inc.). Chemiluminescence was detected using an ECL kit (Advansta, Inc., Menlo Park, CA, USA) and a multiple Gel DOC system (Fujifilm, Tokyo, Japan). The membrane was probed with primary antibodies overnight at $4{ }^{\circ} \mathrm{C}$, followed by the application of the following secondary antibodies for $1 \mathrm{~h}$ at room temperature: Horseradish peroxidase (HRP)-conjugated goat anti-mouse IgG (cat. no. K0211589; 1:3,000) or HRP-conjugated goat anti-rabbit IgG (cat. no. K0211708; 1:3,000; both KOMABiotech, Seoul, Korea). 
$\mathbf{A}$

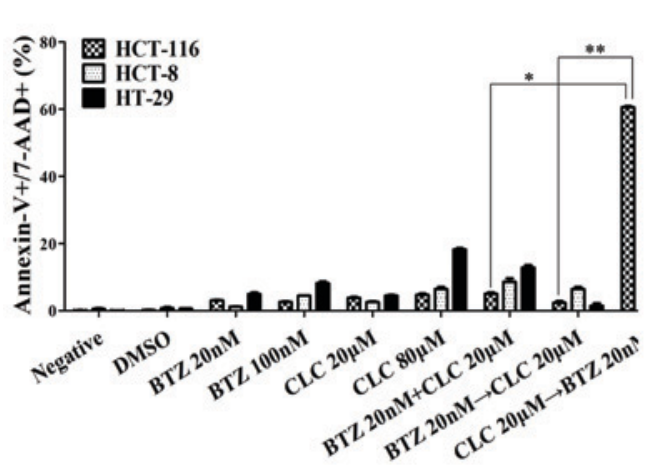

C

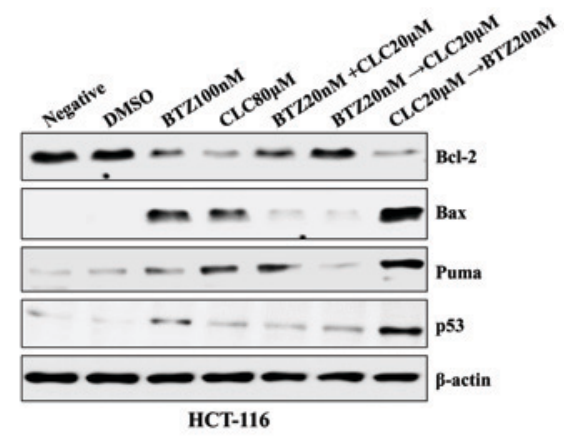

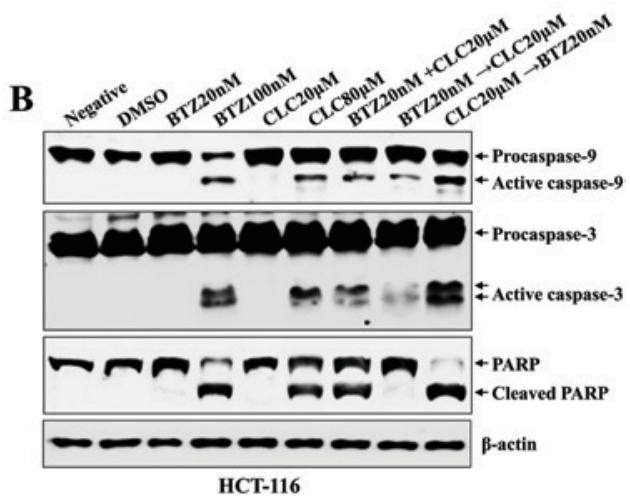

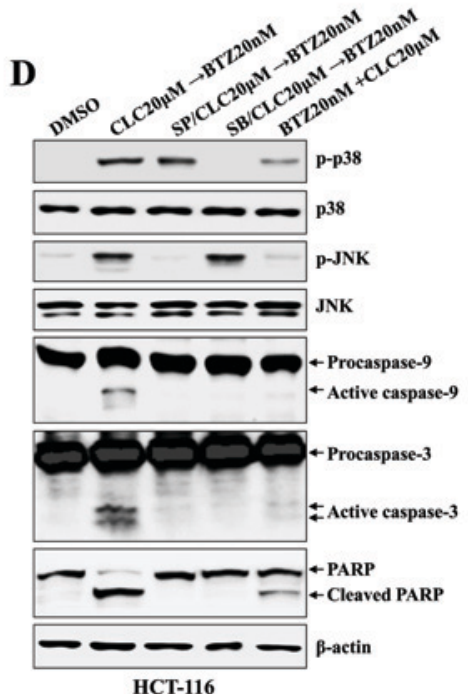

Figure 2. Sequential treatment with CLC and BTZ enhances apoptotic death of colon cancer cells. HCT-116 cells were treated with BTZ or CLC individually or in combination. (A) Annexin-V/7-AAD staining was used to estimate the rate of apoptosis. The number of late-stage apoptotic cells (annexin- $\left.\mathrm{V}^{+} / 7-\mathrm{AAD}^{+}\right)$ was calculated by flow cytometry. ${ }^{*} \mathrm{P}<0.01 ;{ }^{* * *} \mathrm{P}<0.005$. Cells from each indicated condition were harvested and blotted with the indicated antibodies, including (B) caspases (procaspase-9, active caspase-9, procaspase-3, active caspase-3 and PARP (full-length PARP, cleaved PARP), and (C) Bcl-2, Bax, PUMA and p53. $\beta$-actin served as an internal control. (D) To inhibit the activation of JNK or p38-mitogen-activated protein kinase, cells were pre-treated with SP600125 $(20 \mu \mathrm{M})$ or SB203580 $(10 \mu \mathrm{M})$ for $2 \mathrm{~h}$. The expression of caspase-9, caspase-3 and cleaved PARP were detected by western blotting. The results are representative of three independent experiments. CLC, celecoxib; BTZ, bortezomib; 7-AAD, 7-aminoactinomycin D; PARP, poly (ADP-ribose) polymerase; negative, non-treated cell; DMSO, dimethyl sulfoxide control; p-, phosphorylated; JNK, c-Jun N-terminal kinase; PUMA, p53-upregulated modulator of apoptosis.

Confocal microscopy. Cells were permeabilized with permeabilization buffer ( $0.1 \%$ saponin in PBS), incubated with primary antibodies against LC3-I/II (cat. no. 4108; 1:200; Cell Signaling Technology) and lysosomal associated membrane protein 1 (LAMP1; cat. no. 4108; 1:100; Santa Cruz Biotechnology) for $30 \mathrm{~min}$ at $4^{\circ} \mathrm{C}$, and incubated with FITC-conjugated goat anti-rabbit IgG (cat. no. F9887; 1:400) or PE-conjugated secondary goat anti-mouse IgG (cat. no. P9287; 1:400) (both Sigma-Aldrich; Merck KGaA) for $20 \mathrm{~min}$ at $4^{\circ} \mathrm{C}$. Cells were mounted using Dako fluorescent mounting medium (Agilent Technologies, Inc., Santa Clara, CA, USA) and observed with a confocal laser scanning microscope at $\mathrm{x} 400$ magnification. Images were acquired using Confocal Microscopy Software version 3.0 (Carl Zeiss AG, Oberkochen, Germany).

Statistical analysis. Data are expressed as the mean \pm SD. Statistical analysis was conducted using one-way analysis of variance (ANOVA) using SigmaPlot software (version 10.0; Systat Software, Inc., San Jose, CA, USA). Bonferroni post hoc analysis was performed following ANOVA for multiple comparisons. $\mathrm{P}<0.05$ was considered to indicate a statistically significant difference.

\section{Results}

Sequential treatment with celecoxib and bortezomib enhances the apoptotic signaling pathway through the up-regulation of p53, JNK, and p38-MAPK expression. Although sub-toxic doses of each drug in isolation (bortezomib $20 \mathrm{nM}$; celecoxib $20 \mu \mathrm{M}$ ) slightly suppressed cell viability, the effect of the treatment with bortezomib $(20 \mathrm{nM})$ and celecoxib $(20 \mu \mathrm{M})$ together on cell survival depended on the order in which the drugs were applied. When colon cancer cells were treated with celecoxib (CLC) then bortezomib (BTZ) (CLC $20 \mu \mathrm{M}$ then BTZ $20 \mathrm{nM}$ ), cell viability was significantly decreased compared with the group treated with bortezomib and then celecoxib (BTZ $20 \mathrm{nM}$ then CLC $20 \mu \mathrm{M})(\mathrm{P}<0.01$, CLC $20 \mu \mathrm{M}$ then BTZ $20 \mathrm{nM}$ vs. BTZ $20 \mathrm{nM}$ then CLC $20 \mu \mathrm{M}$ ) (Fig. 1A). The viability of colon cancer cells sequentially treated with celecoxib and bortezomib also decreased in a celecoxib dose-dependent manner. Notably, the effect of consecutive 
A

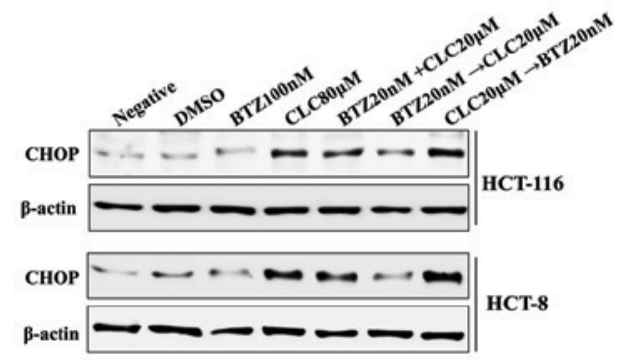

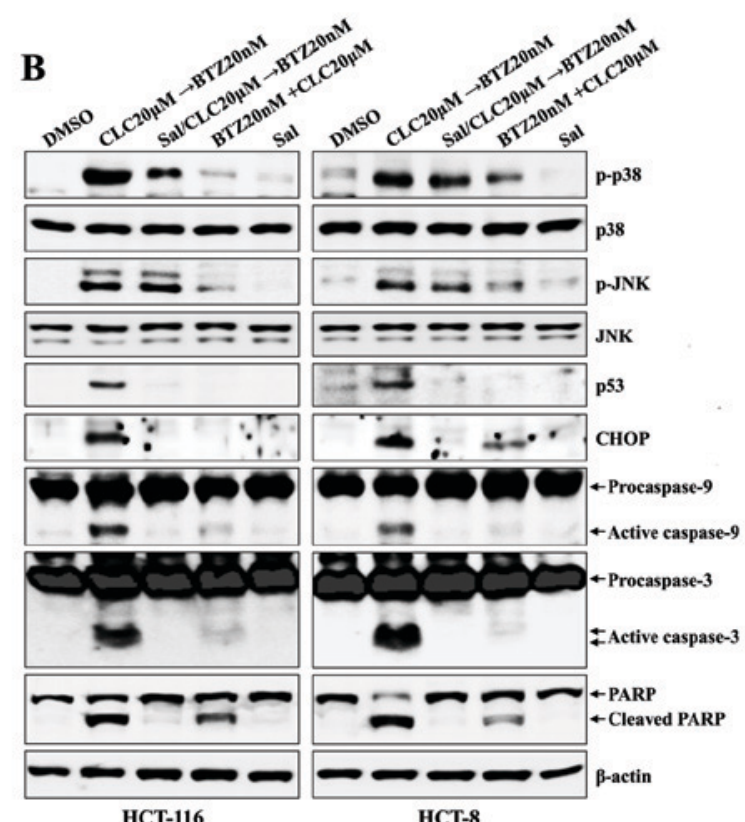

HCT-116
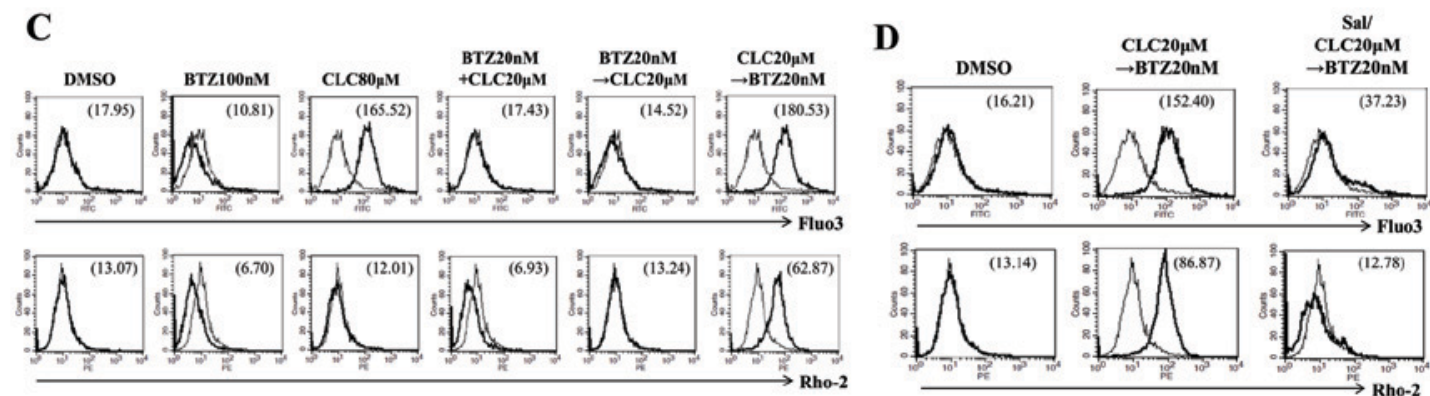

Figure 3. Sequential treatment with CLC and BTZ induces apoptosis in colon cancer cells through ER stress-mediated calcium translocation. HCT-116 cells were treated with BTZ or CLC alone or in combination. (A) Cells treated as indicated were blotted with antibodies against CHOP. (B) Cells treated as indicated were blotted with a range of antibodies. $\beta$-actin served as an internal control. To inhibit endoplasmic reticulum stress, cells were pre-incubated with Sal $(2 \mu \mathrm{M})$ for $1 \mathrm{~h}$. (C) Cytosolic and (D) mitochondrial $\mathrm{Ca}^{2+}$ levels in HCT-116 cells were determined using Fluo3-AM and Rhod2-AM, respectively. To block endoplasmic reticulum stress, cells were pre-incubated with Sal $(2 \mu \mathrm{M})$ for $1 \mathrm{~h}$. The results are representative of three independent experiments. CLC, celecoxib; BTZ, bortezomib; neg, non-treated cell; CHOP, CCAAT-enhancer-binding protein homologous protein; Sal, salubrinal; DMSO, dimethyl sulfoxide control; PARP, poly (ADP-ribose) polymerase.

treatment with celecoxib and bortezomib on cell viability differed significantly depending on the doses of celecoxib $(\mathrm{P}<0.01, \mathrm{CLC} 2.5 \mu \mathrm{M}$ then BTZ $20 \mathrm{nM}$ vs. CLC $20 \mu \mathrm{M}$ then BTZ $20 \mathrm{nM}$ ) (Fig. 1B).

Sequential treatment with celecoxib followed by bortezomib synergistically increased the apoptotic cell death of colon cancer cells $(\mathrm{P}<0.01$, co-treatment with bortezomib and celecoxib vs. celecoxib $\rightarrow$ bortezomib; $\mathrm{P}<0.005$, bortezomib $\rightarrow$ celecoxib vs. celecoxib $\rightarrow$ bortezomib; Fig. 2A), which was associated with the activation and cleavage of caspase-9, caspase-3 and PARP (Fig. 2B). Furthermore, colon cancer cells treated with celecoxib followed by bortezomib exhibited decreased Bcl-2 expression, and increased Bax, p53 and PUMA expression, compared with any other single or combination treatment (Fig. 2C). The expression of p-JNK and p-p38-MAPK, which are required for the initiation of apoptosis, was induced in the HCT-116 cells sequentially treated with celecoxib followed by bortezomib; however, the expression of p-ERK was downregulated (Fig. 2D). With pre-exposure to SB203580 (a p38-MAPK inhibitor) or SP600125 (a JNK inhibitor), the activation of MAPKs and caspases in the colon cancer cells by treatment with celecoxib followed by bortezomib was inhibited (Fig. 2D). These data suggest that sequential treatment with celecoxib and bortezomib enhances the synergistic induction of apoptotic death in human colon cancer cells in a manner that depends on the order in which the drugs are applied.

Sequential treatment with celecoxib followed by bortezomib induces apoptosis in colon cancer cells through ER stress-mediated calcium translocation. Whether treatment with celecoxib followed by bortezomib stimulated ER stress-mediated mitochondrial dysfunction, in which the translocation of calcium from the ER induces mitochondria-dependent apoptosis (15), was investigated next. The treatment of cells with celecoxib followed by bortezomib resulted in the increased induction of CHOP, compared with cells co-treated with alternative drug combinations, or with bortezomib followed by celecoxib (Fig. 3A). Pre-exposure to salubrinal (an ER stress inhibitor) of the colon cancer cells inhibited the expression of p53 and CHOP, and prevented the cleavage of caspase-9, caspase-3 and PARP subsequent to 

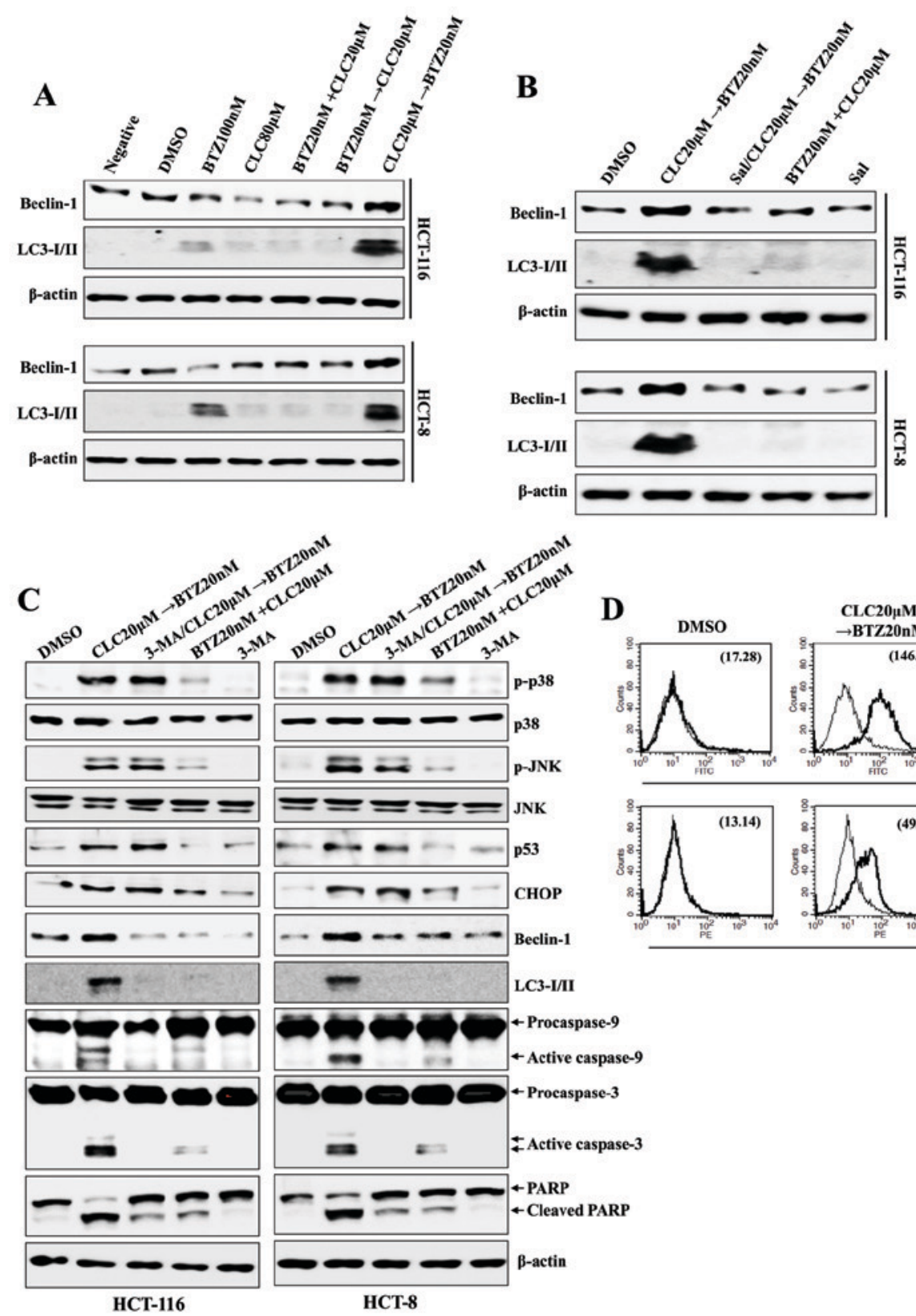

Figure 4. Sequential treatment with CLC and BTZ provokes ER stress-mediated autophagy-associated cell death in colon cancer cells. HCT-116 cells were treated with BTZ or CLC alone or in combination. (A-C) Total lysates of cells under each indicated condition were harvested and blotted with the indicated antibodies. $\beta$-actin served as an internal control. (B) To block ER stress, cells were pre-incubated with salubrinal ( $2 \mu \mathrm{M})$ for $1 \mathrm{~h}$. (C) To inhibit the autophagic signal, cells were pre-treated with 3-MA $(10 \mathrm{mM})$ for $2 \mathrm{~h}$. (D) Cytosolic and mitochondrial $\mathrm{Ca}^{2+}$ levels in HCT-116 cells were determined using Fluo3-AM and Rhod2-AM, respectively. The results are representative of three independent experiments. CLC, celecoxib; BTZ, bortezomib; ER, endoplasmic reticulum; 3-MA, 3-methyladenine; negative, non-treated cell; LC3-I/II, microtubule-associated protein 1A/1B-light chain 3; DMSO, dimethyl sulfoxide control; PARP, poly (ADP-ribose) polymerase; p-, phosphorylated; JNK, c-Jun N-terminal kinase; CHOP, CCAAT-enhancer-binding protein homologous protein.

treatment with celecoxib followed by bortezomib (Fig. 3B). Treatment with celecoxib followed by bortezomib, and high doses of celecoxib alone, increased the cytosolic and mitochondrial $\mathrm{Ca}^{2+}$ levels in colon cancer cells; pre-treatment with salubrinal inhibited this effect (Fig. 3C and D). The data collectively suggest that ER stress-mediated apoptosis of colon cancer cells treated with celecoxib followed by bortezomib is associated, at least partially, with increases in cytosolic and mitochondrial $\mathrm{Ca}^{2+}$.

Treatment with celecoxib followed by bortezomib induces $E R$ stress-mediated autophagy-associated cell death in colon cancer cells. Whether treatment with celecoxib followed by bortezomib was also connected to autophagy-associated cell death was examined. Treatment with celecoxib followed by bortezomib induced the expression of Beclin-1 and autophagosome-associated LC3-I/II proteins, which are associated with autophagy-associated cell death (Fig. 4A); however, pre-treatment with salubrinal decreased the expression of Beclin-1 and LC3-I/II by treatment with celecoxib followed by bortezomib (Fig. 4B). Although pre-exposure to the autophagy inhibitor 3-MA inhibited the autophagy-associated cell death of colon cancer cells subsequent to treatment with celecoxib followed by bortezomib, the expression levels of CHOP, p53 and p-MAPKs 

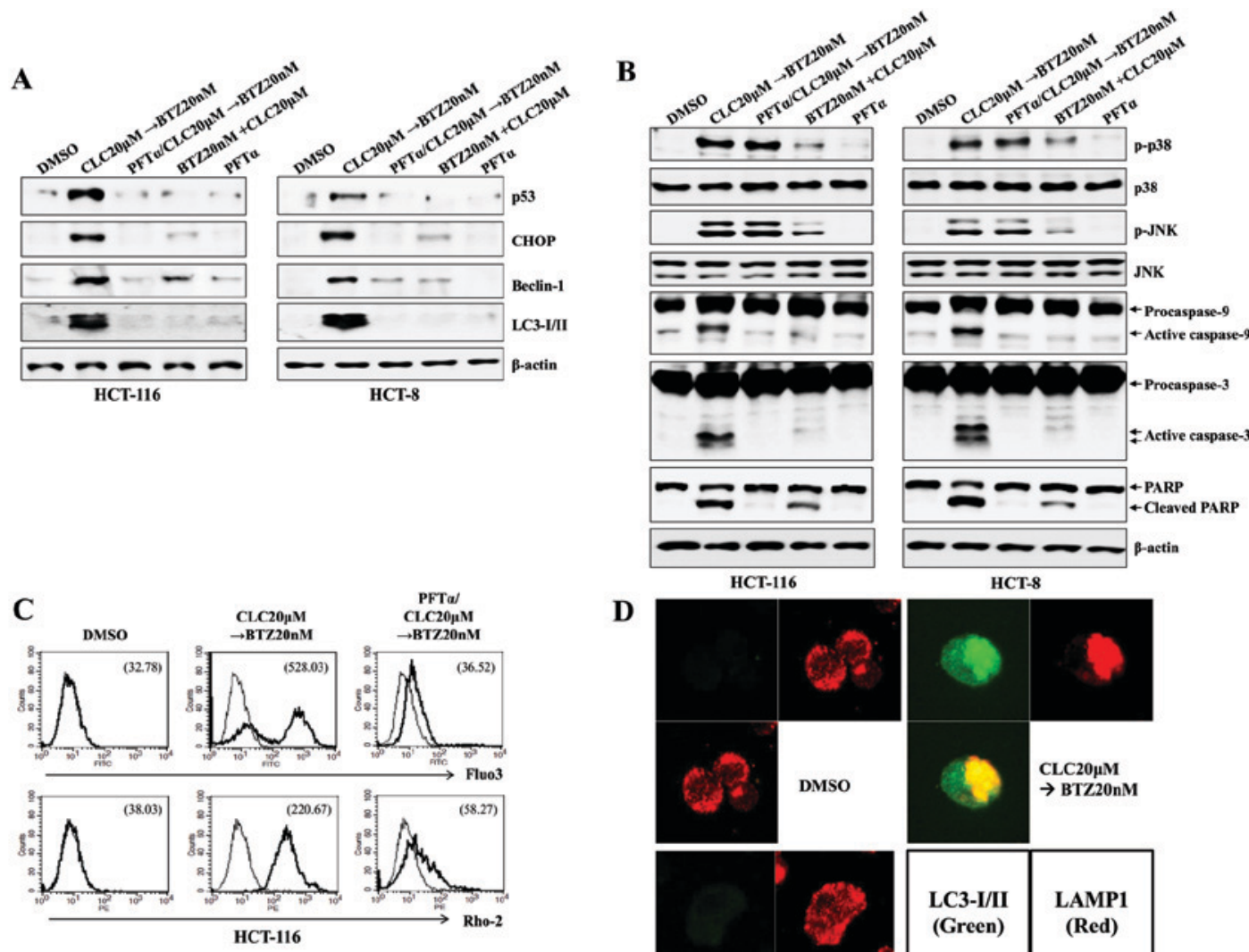

D

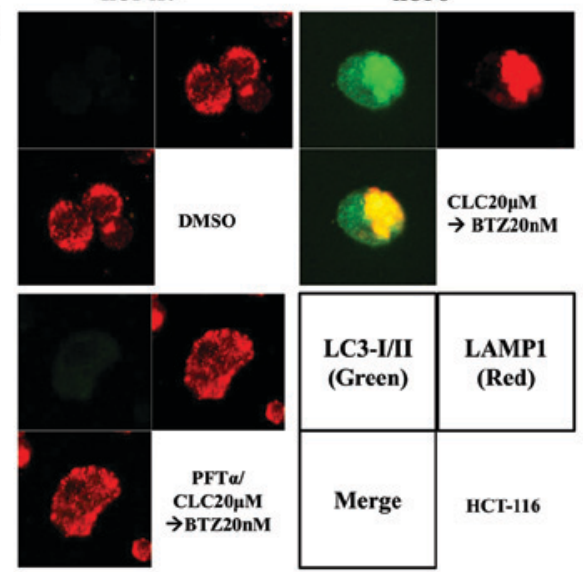

Figure 5. The expression of p53 is dispensable for the endoplasmic reticulum stress-mediated autophagy-associated cell death of colon cancer cells treated sequentially with CLC and BTZ. HCT-116 or HCT- 8 cells were pre-incubated with PTF- $\alpha(50 \mu \mathrm{M})$ for $1 \mathrm{~h}$. (A and B) Cells in each indicated condition were harvested and blotted with the indicated antibodies. $\beta$-actin served as the internal control. (C) Cytosolic and mitochondrial Ca ${ }^{2+}$ levels in HCT-116 cells were determined using Fluo3-AM and Rhod2-AM, respectively. (D) Subcellular distribution of LC3-I/II and LAMP1 in HCT-116 cells. Cells were observed under a confocal microscope (magnification, x400). Green fluorescence indicates LC3-I/II, and red fluorescence indicates LAMP1. The results are representative of three independent experiments. CLC, celecoxib; BTZ, bortezomib; PFT- $\alpha$, pifithrin- $\alpha$; LC3-I/II, microtubule-associated protein 1A/1B-light chain 3; LAMP1, lysosomal-associated membrane protein 1; DMSO, dimethyl sulfoxide control; CHOP, CCAAT-enhancer-binding protein homologous protein; p-, phosphorylated; JNK, c-Jun N-terminal kinase; PARP, poly (ADP-ribose) polymerase.

remained upregulated (Fig. 4C). Furthermore, treatment of the cells with 3-MA had no effect on the levels of cytosolic or mitochondrial $\mathrm{Ca}^{2+}$ subsequent to treatment with celecoxib followed by bortezomib (Fig. 4D). These data suggest that ER stress-associated apoptotic signaling in colon cancer cells leads to the induction of autophagy-associated cell death subsequent to treatment with celecoxib followed by bortezomib.

p53 expression regulates ER stress-mediated autophagy-associated cell death following treatment with celecoxib followed by bortezomib. ER stress is associated with the induction of $\mathrm{p} 53$ expression (16), and the level of cytoplasmic p53 serves a critical role in regulating ER stress-associated $\mathrm{Ca}^{2+}$ homeostasis (17). Treatment with celecoxib followed by bortezomib induced the expression of p53 and increased cytosolic and mitochondrial $\mathrm{Ca}^{2+}$ levels. Next, it was investigated whether the increased expression of p53 by treatment with celecoxib followed by bortezomib was responsible for the ER stress/autophagy-associated cell death due to the induction of apoptosis. Pre-treatment with PFT- $\alpha$, a selective $p 53$ inhibitor, not only prevented the increases in CHOP, Beclin-1 and LC-3I/II expression (Fig. 5A), but also reduced the cleavage of caspase-9, caspase- 3 and PARP in colon cancer cells treated with celecoxib followed by bortezomib (Fig. 5B). When PFT- $\alpha$ was applied in cells treated with celecoxib followed by bortezomib, intracellular and mitochondrial levels of $\mathrm{Ca}^{2+}$ were reduced (Fig. 5C), and the co-localization of LAMP1 and LC3-I/II was inhibited, compared with the cells treated with celecoxib followed by bortezomib (Fig. 5D). These data suggest that the expression of p53 in colon cancer cells serves a role in inducing ER stress/autophagy-associated cell death subsequent to treatment with celecoxib followed by bortezomib.

Treatment with celecoxib followed by bortezomib induces the autophagy-associated cell death of colon cancer cells even in the absence of $p 53$ expression. Whether the treatment with celecoxib followed by bortezomib affects ER stress-mediated autophagy-associated cell death in $\mathrm{p} 53^{-\digamma}$ colon cancer cells was then investigated. The treatment of $\mathrm{p} 53^{-/}$HCT-116 cells with celecoxib followed by bortezomib induced the phosphorylation 


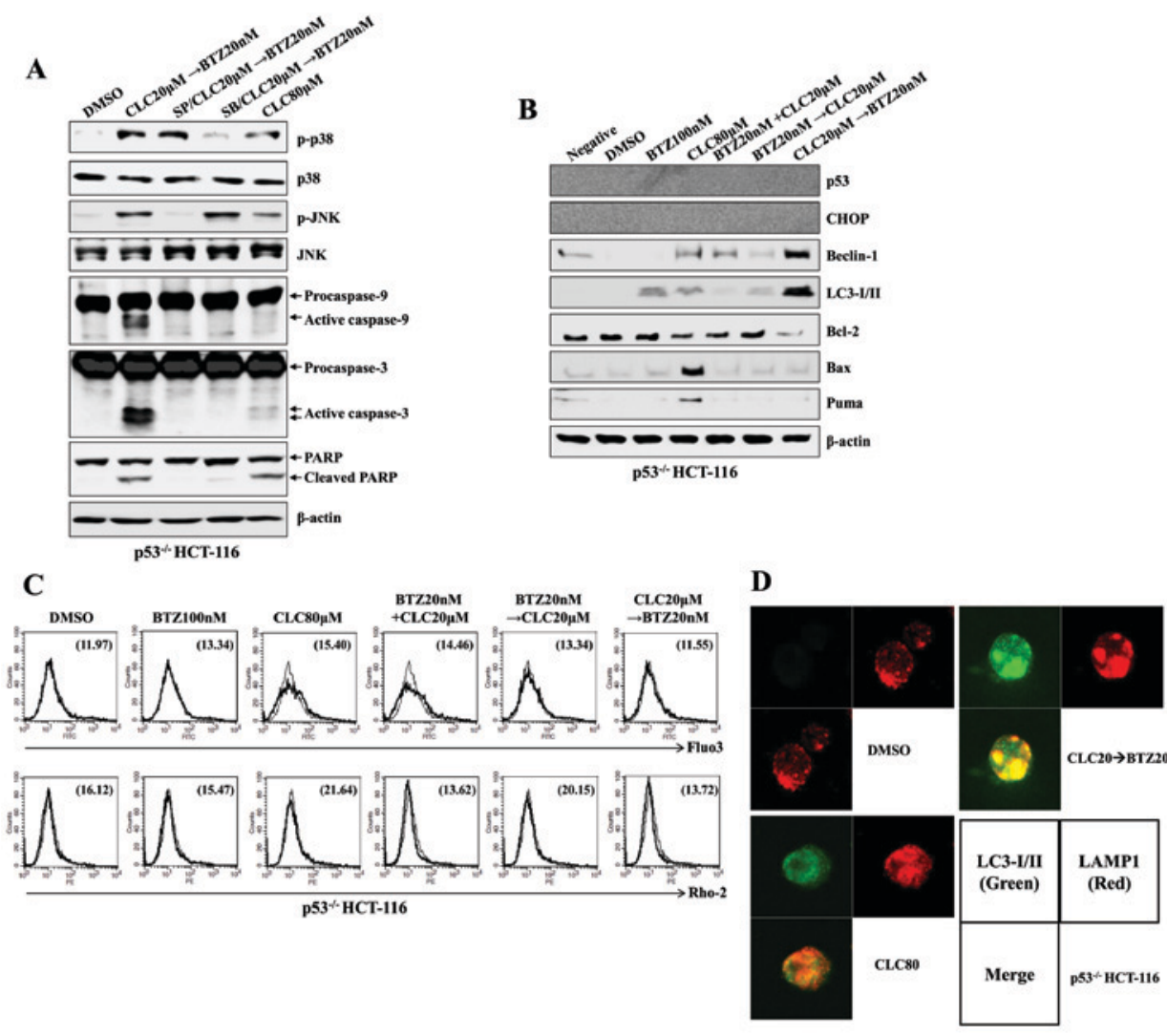

Figure 6. Sequential treatment with CLC and BTZ induces the autophagy-associated cell death of p53 $3^{-\leftarrow}$ colon cancer cells. p53 ${ }^{-/}$HCT-116 cells were treated with BTZ or CLC alone or in combination. (A and B) Total cell lysates of each condition were harvested and blotted with the indicated antibodies. $\beta$-actin served as an internal control. (C) Cytosolic and mitochondrial $\mathrm{Ca}^{2+}$ levels in HCT-116 cells were determined using Fluo3-AM and Rhod2-AM, respectively. (D) Subcellular distribution of LC3-I/II and LAMP1 in p53/- HCT-116 cells. Cells were observed under a confocal microscope (magnification, x400). Green fluorescence indicates LC3-I/II, and red fluorescence indicates LAMP1. The results are representative of three independent experiments. CLC, celecoxib; BTZ, bortezomib; LC3-I/II, microtubule-associated protein 1A/1B-light chain 3; LAMP1, lysosomal-associated membrane protein 1; DMSO, dimethyl sulfoxide control; p-, phosphorylated; JNK, c-Jun N-terminal kinase; PARP, poly (ADP-ribose) polymerase; negative, non-treated cells; CHOP, CCAAT-enhancer-binding protein homologous protein; Bax; Bcl-associated X; PUMA, p53-upregulated modulator of apoptosis.

of p38-MAPK and JNK and the expression of activated caspase-9 and caspase-3 (Fig. 6A). Furthermore, the induction of Beclin-1 and LC-3I/II expression was observed in $\mathrm{p} 53^{-/-}$ HCT-116 cells treated with celecoxib followed by bortezomib, although the induction of CHOP was not detected (Fig. 6B). Notably, changes to the levels of Bcl-2, Bax and PUMA expression, which are induced by p53, were not observed (Fig. 6B). Although no $\mathrm{Ca}^{2+}$ increase was detected in the cytoplasm or mitochondria of p53/- HCT-116 cells (Fig. 6C), fusion of the autophagosomes and the lysosomes was detected subsequent to treatment with celecoxib followed by bortezomib (Fig. 6D). These data suggest that treatment with celecoxib followed by bortezomib may cause ER stress-mediated autophagy-associated cell death independent of p53 expression.

The expression of p53 regulates intracellular calcium release from the ER to enhance autophagy-associated cell death. As treatment with celecoxib followed by bortezomib increased the autophagy-associated cell death of colon cancer cells regardless of p53 expression, the role of, and association between, intracellular $\mathrm{Ca}^{2+}$ and p53 expression in the ER stress-induced autophagy-associated cell death of colon cancer cells was investigated. The p53-expressing HCT-116 colon cancer cells were more susceptible to apoptotic cell death than $\mathrm{p}^{-/-}$HCT-116 colon cancer cells following treatment with celecoxib followed by bortezomib $(\mathrm{P}<0.05$, p53-expressing HCT-116 compared with p53-null HCT-116; Fig. 7A). In addition, treatment with BAPTA-AM, a calcium chelator, failed to inhibit apoptosis or the cleavage of caspase-3 in $\mathrm{p} 53^{-/}$HCT-116 cells subsequent to treatment with celecoxib followed by bortezomib (\#P<0.05, celecoxib $\rightarrow$ bortezomib in p53-expressing HCT-116 vs. pretreatment with BAPTA-AM, and then celecoxib $\rightarrow$ bortezomib in p53-expressing HCT-116; \#\#P<0.001, pretreatment with BAPTA-AM, and then celecoxib $\rightarrow$ bortezomib in p53-expressing HCT-116 vs. pretreatment with BAPTA-AM, and then celecoxib $\rightarrow$ bortezomib in p53-null HCT-116; Fig. 7B). Exposure to BAPTA-AM not only reduced the expression of CHOP, Beclin-1 and LC3-I/II, but also prevented the cleavage of caspase-3 in p53-expressing HCT-116 colon cancer cells treated with celecoxib followed by bortezomib (Fig. 7C); however, treatment with BAPTA-AM failed to inhibit the activation of Beclin-1 and LC3-I/II and prevent the cleavage of caspase-3 in p53 ${ }^{-/}$HCT-116 cells subsequent to treatment with celecoxib followed by bortezomib (Fig. 7C and D). These data suggest that p53 expression is critical for promoting autophagy-associated cell death through the regulation of intracellular $\mathrm{Ca}^{2+}$ released from the ER. 

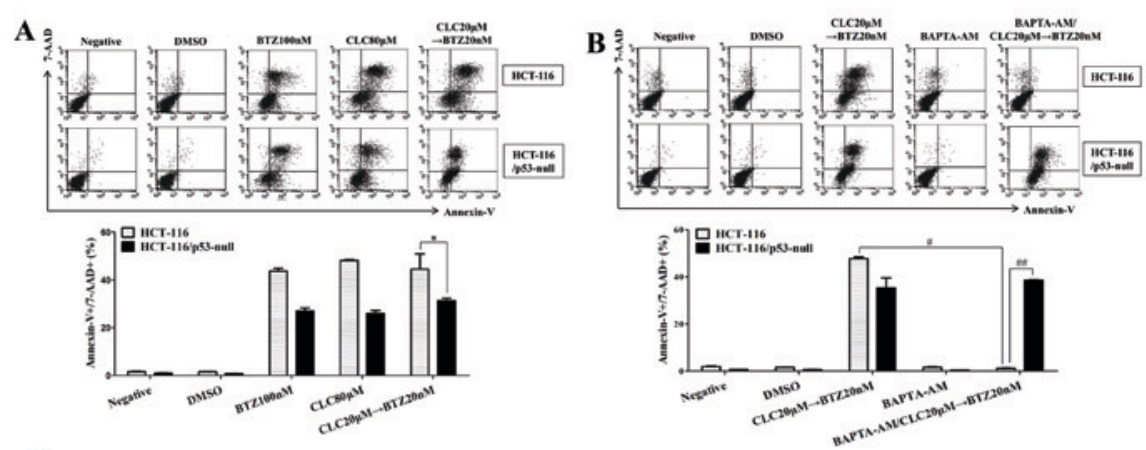

C

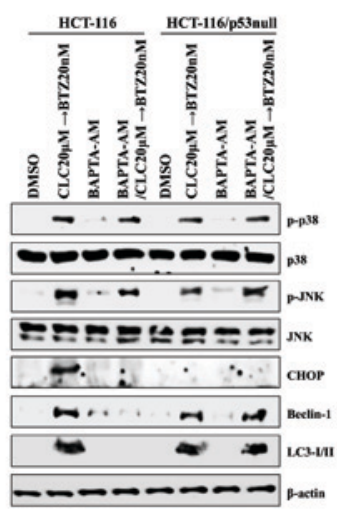

D

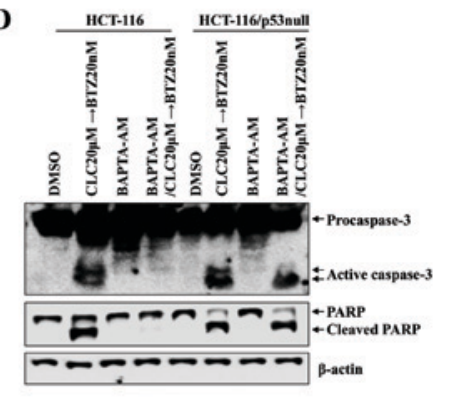

Figure 7. The expression of p53 is critical for endoplasmic reticulum stress-mediated autophagy-associated cell death through the regulation of intracellular

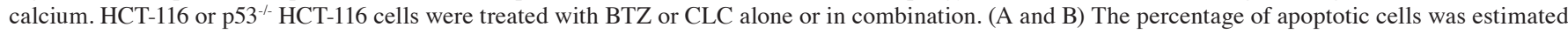
by annexin-V/7-AAD staining. Data are representative of three independent experiments. The number of late-stage apoptotic cells $\left(\right.$ annexin- $\left.\mathrm{V}^{+} / 7-\mathrm{AAD}^{+}\right)$was calculated by flow cytometry. ${ }^{~} \mathrm{P}<0.05 ;{ }^{\#} \mathrm{P}<0.05$ and ${ }^{\# \#} \mathrm{P}<0.001$. (B-D) To block the effect of $\mathrm{Ca}^{2+}$, HCT-116 or p53 ${ }^{--}$HCT-116 cells were pre-incubated with BAPTA-AM $(2 \mu \mathrm{M})$ for $30 \mathrm{~min}$. (C and D) Total cell lysates of each condition were harvested and immunoblotted with the indicated antibodies. $\beta$-actin served as an internal control. The results are representative of three independent experiments. BTZ, bortezomib; CLC, celecoxib; 7-AAD, 7-aminoactinomycin D; negative, non-treated cells; DMSO, dimethyl sulfoxide control; p-, phosphorylated; JNK, c-Jun N-terminal kinase; CHOP, CCAAT-enhancer-binding protein homologous protein; LC3-I/II, microtubule-associated protein 1A/1B-light chain 3; PARP, poly (ADP-ribose) polymerase.

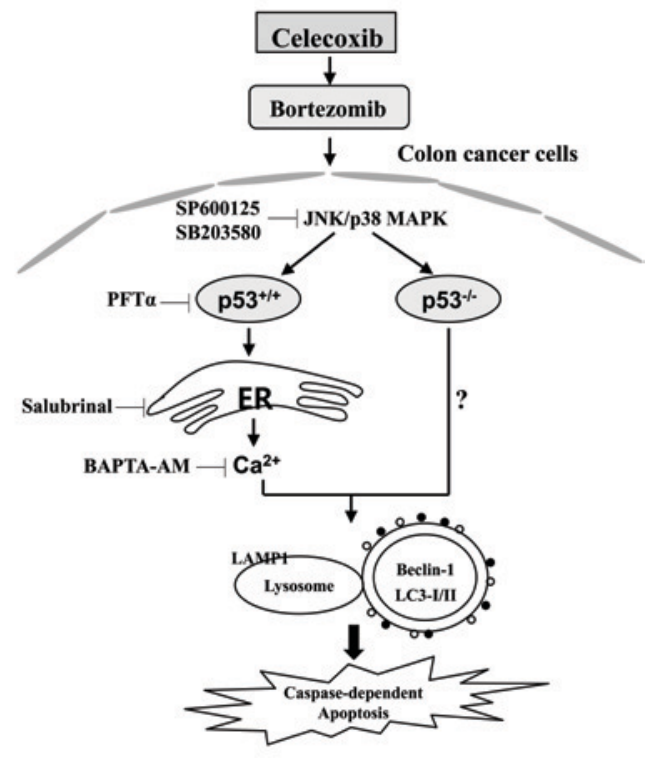

Figure 8. Schematic diagram of the intracellular signaling pathway following sequential treatment with celecoxib and bortezomib in human colorectal cancer cells. The expression of $\mathrm{p} 53$ is required for ER stress-mediated $\mathrm{Ca}^{2+}$ translocation to promote autophagy-associated cell death following the sequential treatment with celecoxib and bortezomib. The consecutive treatment of colon cancer cells with celecoxib and bortezomib also enhances autophagy-associated cell death in $\mathrm{p} 53^{-/}$colon cancer cells. ER, endoplasmic reticulum; JNK, c-Jun N-terminal kinase; p38 MAPK, p38 mitogen-activated protein kinase; LAMP1, lysosomal-associated membrane protein 1; LC3-I/II, microtubule-associated protein 1A/1B-light chain 3.

\section{Discussion}

Bortezomib and celecoxib or dimethyl-celecoxib (DMC) as a novel drug combination enhance apoptotic cell death through the upregulation of ER stress in addition to the activation of JNK in glioblastoma (18). Pre-treatment with bortezomib enhances the rate of apoptosis induced by treatment with celecoxib through the induction of cell cycle arrest and ER stress (19). In the present study, the anticancer activity was enhanced by the treatment with celecoxib followed by bortezomib; this was associated with autophagy-associated cell death, regardless of p53 expression. Furthermore, the expression of p53 was required for ER stress-mediated $\mathrm{Ca}^{2+}$ translocation to promote autophagy-associated cell death following treatment with celecoxib followed by bortezomib (Fig. 8).

The anticancer activity of celecoxib has been demonstrated in various animal tumor models and may potentially be useful for the treatment of colorectal cancer and other tumor types $(20,21)$. Although celecoxib toxicity in tumor cells occurs by toxic precipitation of increased doses of the drug (22), celecoxib also causes ER stress-induced apoptosis in a COX-2-independent manner $(14,23)$. However, the long-term use of high-dose celecoxib is associated with severe gastrointestinal and cardiovascular adverse effects (24). Additionally, the combination treatment of colorectal cancer cells with celecoxib and other chemotherapeutic agents induces autophagy-mediated drug resistance (14). Although bortezomib exhibits a unique 
mechanism for anticancer activity, it also blocks the anticancer effect of the ER stress-inducing agents thapsigargin and tunicamycin (8). The induction of autophagy and the ER stress response was demonstrated to protect MCF7 breast cancer cells from bortezomib-induced cell death (25). On the basis of these results, the limited effectiveness of celecoxib and bortezomib against cancer cells has led to a search for therapeutic combination regimens with other agents.

Persistent or intense ER stress induces different effects on normal ER function and induces cell death or apoptosis (26). The disturbance of autophagy also renders cells vulnerable to ER stress, and autophagy activation has been linked to cell death through the regulation of ER stress $(11,27)$. In the present study, the combination of celecoxib followed by bortezomib was the most efficient regimen for the induction of ER stress-mediated autophagy-associated cell death, compared with the groups treated with single drugs alone or with other co-treatment regimens. Although the inhibition of autophagy by 3-MA suppressed the generation of autophagolysosomes, leading to autophagy-associated cell death, 3-MA had no effect on the inhibition of CHOP and p53 expression in colon cancer cells sequentially treated with celecoxib and bortezomib. Exposure to celecoxib followed by bortezomib induced the generation of autophagolyso-

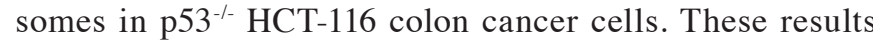
suggest that ER stress is not a critical regulation step for stimulating autophagy-associated cell death in colon cancer cells following the serial treatment with celecoxib and bortezomib.

Intracellular $\mathrm{Ca}^{2+}$ released due to ER stress as a result of various stimuli is absorbed by mitochondria. Once calcium is taken into the mitochondria, it causes the activation of the apoptotic pathway (28). Giorgi et al (17) demonstrated that wild-type cytoplasmic p53 at the ER binds to $\mathrm{Ca}^{2+}$ pumps to modulate $\mathrm{Ca}^{2+}$ homeostasis and mitochondrial function. In the present study, sequential treatment with celecoxib and bortezomib also promoted ER stress-mediated apoptosis through $\mathrm{Ca}^{2+}$ translocation and changes in the intracellular and mitochondrial $\mathrm{Ca}^{2+}$ concentration in p53-expressing HCT-116 cells. Calcium chelation with BAPTA-AM decreased the expression levels of CHOP and inhibited autophagy-associated cell death in wild-type HCT-116 colon cancer cells. Although p53-expressing HCT-116 cells were more sensitive to autophagy-associated cell death than $\mathrm{p} 53^{-1-}$ HCT-116 cells, the treatment of p53 ${ }^{-/}$HCT-116 cells with celecoxib followed by bortezomib also induced apoptosis and the expression of Beclin-1 and LC3-I/II, but not CHOP. These results suggest that the sequential drug combination can cause apoptosis in a p53-independent manner, although for full effectiveness, p53 expression is required to induce the release of $\mathrm{Ca}^{2+}$ from the ER.

The overexpression of Bcl-2 inhibits $\mathrm{Ca}^{2+}$ transfer from the ER to the mitochondria and prevents apoptosis (29). Bcl-2 proteins have been shown to inhibit autophagy by disrupting Bcl-2/Bcl- $\mathrm{X}_{\mathrm{L}}$-Beclin-1 complexes (30); however, it remains unclear how Bcl-2-family proteins are associated with autophagy-associated cell death in the absence of p53 expression. In the present study, only Bcl-2 was decreased in p53 $3^{-/}$HCT-116 colon cells sequentially treated with celecoxib and bortezomib. On the basis of these results, further studies are required to investigate how the combined treatment of celecoxib followed by bortezomib induces autophagy-mediated cell death in the absence of p53 expression.

Taken together, the results of the present study provide information about the optimal order for anticancer drug administration and the role of calcium and p53 on ER stress-mediated autophagy-associated cell death in colon cancer cells subsequent to treatment with celecoxib followed by bortezomib.

\section{Acknowledgements}

The present study was supported by a 2016 Inje University research grant (grant no. 20170021).

\section{References}

1. Arico S, Pattingre S, Bauvy C, Gane P and Barbat A, Codogno P and Ogier-Denis E: Celecoxib induces apoptosis by inhibiting 3 -phosphoinositide-dependent protein kinase-1 activity in the human colon cancer HT-29 cell line. J Biol Chem 277: 27613-27621, 2002.

2. Lynch PM, Ayers GD, Hawk E, Richmond E, Eagle C, Woloj M, Church J, Hasson H, Patterson S, Half E and Burke CA: The safety and efficacy of celecoxib in children with familial adenomatous polyposis. Am J Gastroenterol 105: 1437-1443, 2010.

3. Tsutsumi S, Namba T, Tanaka KI, Arai Y, Ishihara T, Aburaya M, Mima S, Hoshino T and Mizushima T: Celecoxib upregulates endoplasmic reticulum chaperones that inhibit celecoxib-induced apoptosis in human gastric cells. Oncogene 25: 1018-1029, 2006.

4. Tsutsumi S, Gotoh T, Tomisato W, Mima S, Hoshino T, Hwang HJ, Takenaka H, Tsuchiya T, Mori M and Mizushima T: Endoplasmic reticulum stress response is involved in nonsteroidal anti-inflammatory drug-induced apoptosis. Cell Death Differ 11: 1009-1016, 2004.

5. Lin WC, Chuang YC, Chang YS, Lai MD, Teng YN, Su IJ, Wang CC, Lee KH and Hung JH: Endoplasmic reticulum stress stimulates p53 expression through NF- $\mathrm{BB}$ activation. PLoS One 7: e39120, 2012.

6. Edagawa M, Kawauchi J, Hirata M, Goshima H, Inoue M, Okamoto T, Murakami A, Maehara Y and Kitajima S: Role of activating transcription factor 3 (ATF3) in endoplasmic reticulum (ER) stress-induced sensitization of p53-deficient human colon cancer cells to tumor necrosis factor (TNF)-related apoptosis-inducing ligand (TRAIL)-mediated apoptosis through up-regulation of death receptor 5 (DR5) by zerumbone and celecoxib. J Biol Chem 289: 21544-21561, 2014

7. Ludwig H, Khayat D, Giaccone G and Facon T: Proteasome inhibition and its clinical prospects in the treatment of hematologic and solid malignancies. Cancer 104: 1794-1807, 2005.

8. Nawrocki ST, Carew JS, Pino MS, Highshaw RA, Dunner K Jr, Huang P, Abbruzzese JL and McConkey DJ: Bortezomib sensitizes pancreatic cancer cells to endoplasmic reticulum stress-mediated apoptosis. Cancer Res 65: 11658-11666, 2005.

9. Yu J, Tiwari S, Steiner P and Zhang L: Differential apoptotic response to the proteasome inhibitor Bortezomib [VELCADE, PS-341] in Bax-deficient and p21-deficient colon cancer cells. Cancer Biol Ther 2: 694-699, 2003.

10. Lum JJ, Bauer DE, Kong M, Harris MH, Li C, Lindsten T and Thompson CB: Growth factor regulation of autophagy and cell survival in the absence of apoptosis. Cell 120: 237-248, 2005.

11. Ogata M, Hino S, Saito A, Morikawa K, Kondo S, Kanemoto S, Murakami T, Taniguchi M, Tanii I, Yoshinaga K, et al: Autophagy is activated for cell survival after endoplasmic reticulum stress. Mol Cell Biol 26: 9220-9231, 2006.

12. Yang $Z$ and Klionsky DJ: Eaten alive: A history of macroautophagy. Nat Cell Biol 12: 814-822, 2010.

13. Kao C, Chao A, Tsai CL, Chuang WC, Huang WP, Chen GC, Lin CY, Wang TH, Wang HS and Lai CH: Bortezomib enhances cancer cell death by blocking the autophagic flux through stimulating ERK phosphorylation. Cell Death Dis 5: e1510, 2014.

14. Huang S and Sinicrope FA: Celecoxib-induced apoptosis is enhanced by ABT-737 and by inhibition of autophagy in human colorectal cancer cells. Autophagy 6: 256-269, 2010. 
15. Deniaud A, Sharaf el dein O, Maillier E, Poncet D, Kroemer G, Lemaire $C$ and Brenner $C$ : Endoplasmic reticulum stress induces calcium-dependent permeability transition, mitochondrial outer membrane permeabilization and apoptosis. Oncogene 27: 285-299, 2008

16. Li J, Lee B and Lee AS: Endoplasmic reticulum stress-induced apoptosis: Multiple pathways and activation of p53-up-regulated modulator of apoptosis (PUMA) and NOXA by p53. J Biol Chem 281: 7260-7270, 2006.

17. Giorgi C, Bonora M, Sorrentino G, Missiroli S, Poletti F, Suski JM, Galindo Ramirez F, Rizzuto R, Di Virgilio F, Zito $\mathrm{E}$, et al: p53 at the endoplasmic reticulum regulates apoptosis in a Ca2+-dependent manner. Proc Natl Acad Sci USA 112: 1779-1784, 2015

18. Kardosh A, Golden EB, Pyrko P, Uddin J, Hofman FM, Chen TC Louie SG, Petasis NA and Schönthal AH: Aggravated endoplasmic reticulum stress as a basis for enhanced glioblastoma cell killing by bortezomib in combination with celecoxib or its non-coxib analogue, 2,5-dimethyl-celecoxib. Cancer Res 68 843-851, 2008

19. Kim JE, Lee JI, Jin DH, Lee WJ, Park GB, Kim S, Kim YS, Wu TC, Hur DY and Kim D: Sequential treatment of HPV E6 and E7-expressing TC-1 cells with bortezomib and celecoxib promotes apoptosis through p-p38 MAPK-mediated downregulation of cyclin D1 and CDK2. Oncol Rep 31: 2429-2437, 2014.

20. Altorki NK, Keresztes RS, Port JL, Libby DM, Korst RJ, Flieder DB, Ferrara CA, Yankelevitz DF, Subbaramaiah K, Pasmantier MW and Dannenberg AJ: Celecoxib, a selective cyclo-oxygenase-2 inhibitor, enhances the response to preoperative paclitaxel and carboplatin in early-stage non-small-cell lung cancer. J Clin Oncol 21: 2645-2650, 2003.

21. Masferrer JL, Leahy KM, Koki AT, Zweifel BS, Settle SL, Woerner BM, Edwards DA, Flickinger AG, Moore RJ and Seibert K: Antiangiogenic and antitumor activities of cyclooxygenase-2 inhibitors. Cancer Res 60: 1306-1311, 2000.

22. Sacchetti A: Cancer cell killing by Celecoxib: Reality or just in vitro precipitation-related artifact? J Cell Biochem 114: $1434-1444,2013$
23. Cho HY, Thomas S, Golden EB, Gaffney KJ, Hofman FM, Chen TC, Louie SG, Petasis NA and Schönthal AH: Enhanced killing of chemo-resistant breast cancer cells via controlled aggravation of ER stress. Cancer Lett 282: 87-97, 2009.

24. Solomon SD, McMurray JJ, Pfeffer MA, Wittes J, Fowler R, Finn P, Anderson WF, Zauber A, Hawk E and Bertagnolli M; Adenoma Prevention with Celecoxib (APC) Study Investigators: Cardiovascular risk associated with celecoxib in a clinical trial for colorectal adenoma prevention. N Engl J Med 352: 1071-1080, 2005.

25. Milani M, Rzymski T, Mellor HR, Pike L, Bottini A, Generali D and Harris AL: The role of ATF4 stabilization and autophagy in resistance of breast cancer cells treated with Bortezomib. Cancer Res 69: 4415-4423, 2009

26. Boyce M and Yuan J: Cellular response to endoplasmic reticulum stress: A matter of life or death. Cell Death Differ 13: 363-373, 2006.

27. Cuervo AM: Autophagy: In sickness and in health. Trends Cell Biol 14: 70-77, 2004.

28. Oakes SA, Scorrano L, Opferman JT, Bassik MC, Nishino M, Pozzan T and Korsmeyer SJ: Proapoptotic BAX and BAK regulate the type 1 inositol trisphosphate receptor and calcium leak from the endoplasmic reticulum. Proc Natl Acad Sci USA 102: 105-110, 2005.

29. Pinton P, Giorgi C and Pandolfi PP: The role of PML in the control of apoptotic cell fate: A new key player at ER-mitochondria sites. Cell Death Differ 18: 1450-1456, 2011.

30. Levine B, Sinha S and Kroemer G: Bcl-2 family members: Dual regulators of apoptosis and autophagy. Autophagy 4: 600-606, 2008.

This work is licensed under a Creative Commons Attribution-NonCommercial-NoDerivatives 4.0 International (CC BY-NC-ND 4.0) License. 